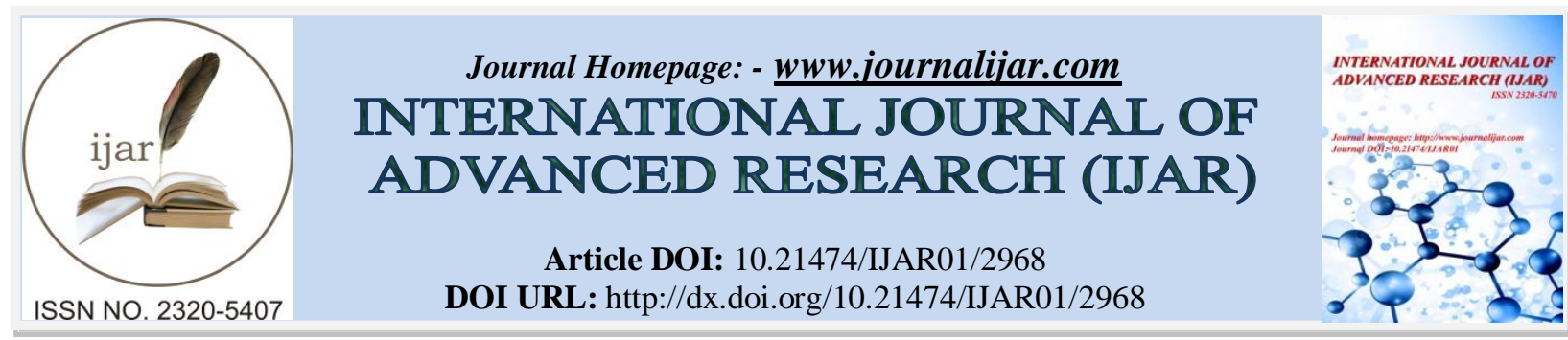

RESEARCH ARTICLE

\title{
SPECTROSCOPIC PROPERTIES OF LITHIUM SODIUM BORATE GLASS BY THE ADDITION OF $\mathrm{MoO}_{3}$
}

1. Department of Physics Rayalaseema University,Kurnool.

2. Deparment of Physics, JNTUH, Hyderabad.

\section{Manuscript Info}

Manuscript History

Received: 30 November 2016

Final Accepted: 26 December 2016

Published: January 2017

Key words:-

Molybdenum ions, Optical absorption, EPR and FTIR

\begin{abstract}
The spectroscopic properties of $\mathrm{Li}_{2} \mathrm{O}-\mathrm{Na}_{2} \mathrm{O}_{3}-\mathrm{B}_{2} \mathrm{O}_{3}$ glass containing different concentrations of $\mathrm{MoO}_{3}$ (ranging from 0 to $1 \mathrm{~mol} \%$ ) were prepared by melt quenching are studied. Spectroscopic (XRD, infrared, optical absorption spectra and EPR) properties of these glasses have been carried out. As the concentration of $\mathrm{MoO}_{3}$ is increased especially beyond $0.4 \mathrm{~mol} \%$, the colour of the glasses increased, which is indicating the reduction of molybdenum ions from the $\mathrm{Mo}^{6+}$ state to the $\mathrm{Mo}^{5+}$ state. The Optical absorption Spectrum contains one broad absorption band around $695 \mathrm{~nm}$ is attributed to the excitation of $\mathrm{Mo}^{5+}$ $\left({ }^{4} d_{1}\right)$ ion. EPR studies reveal Molybdenum ions are expected to exist mainly in the $\mathrm{Mo}^{6+}$ state in the glass network. EPR, FTIR and Optical absorption spectra of paramagnetic ion in the above glasses reveal that the site symmetry of the transition metal ion is elongated octahedral.
\end{abstract}

Copy Right, IJAR, 2016,. All rights reserved.

\section{Introduction:-}

The glasses containing transition metal ions came into prominence because of their notable spectroscopic properties and their suitability for fibre optic communications, luminescent solar energy concentrators (LSC)[1].Among the many glasses, borate glasses have been known to be excellent host materials for transition metal oxides because of their glass forming nature compared to other conventional glass systems. Borate glasses are used as wave-guides, electro-optic switches, electro-optic modulators, magneto-optic materials, solid-state laser materials and non-linear optical parametric converters [2-4]. In addition, they are often used as dielectric and insulating materials and it is known that borate glass constitute a good shield against IR radiation [5]. In general $\mathrm{B}_{2} \mathrm{O}_{3}$ glasses have a property of showing minimum expansion due to the large amount of boric oxide which is of great importance in obtaining thermal durability. It also decreases the tendency for glass to devitrify or crystallize. $\mathrm{B}_{2} \mathrm{O}_{3}$ is a basic glass former because of its higher bond strength, lower cation size and smaller heat of fusion. The ions of molybdenum introduce high activity and selectivity in a series of oxidation reactions of practical importance in the glass matrices [6,7].

Molybdenum oxide belongs to the intermediate class of glass forming oxides. It does not readily form the glass but does so in the presence of the modifier with $\mathrm{MoO}^{4}$. Molybdenum ions in the glasses have been the subject of many investigations due to their catalytic properties. Interesting studies are available on the environment of molybdenum ion in different inorganic glasses [8-13]. Mo-O bond in molybdenum hexavalent oxide is identified as significantly covalent. The Mo ion exist a stable valence state viz., MoV and MoVI in the glass network. Molybdenum ions act both as network formers as well as network modifiers depending upon their concentration and nature of the host network.Mo-O bond in molybdenum hexavalent oxide is identified as covalent. The Mo ion exists at least in two 
stable valence states viz., Mo (V) and Mo (VI) in the glass network. Earlier EPR studies on the glasses containing molybdenum ions have identified the presence of octahedrally coordinated Mo (V) ions along with octrahedral distortion approaching tetragons $[14,15]$. These ions act both as network formers as well as network modifiers depending upon their concentration and nature of the host network. The $\mathrm{Mo}^{6+}$ ions are expected to participate in the glass network with tetrahedral $\mathrm{MoO}_{4}{ }^{2-}$ structural units and may alternate with $\mathrm{BO}^{4}$ tetrahedral units. Most of the studies available on $\mathrm{MoO}_{3}$ containing glasses are on the understanding of their structure by spectroscopic investigations [16, 17] and ionic conductivity studies [18].

In the present work the influence of $\mathrm{MoO}_{3}$ in varying concentrations, on resonance and absorption properties of lithium-sodium-borate glasses are studied. Optical band gaps for both direct and indirect transitions and Urbach energies were calculated and those glasses were also characterized by XRD and FTIR studies.

\section{Experimental:-}

The glasses of the system $20 \mathrm{Li}_{2} \mathrm{O}-10 \mathrm{Na}_{2} \mathrm{O}-(70-\mathrm{X}) \mathrm{B}_{2} \mathrm{O}_{3}\left(\mathrm{X}=\mathrm{MoO}_{3}\right)$ have been prepared by melt quenching technique varying the concentration of molybdenum ranging from $0.2-1.0(\mathrm{~mol} \%)$. The raw materials used were analytical pure $\left(99.5 \%\right.$ ). Appropriate amounts of weighed chemicals $\mathrm{Na}_{2} \mathrm{O}, \mathrm{Li}_{2} \mathrm{O}, \mathrm{B}_{2} \mathrm{O}_{3}, \mathrm{MoO}_{3}$ were grounded thoroughly in a mortar to produce homogeneous mixture. This homogenized mixture was then placed in porcelain crucibles and melted in an electrical furnace at $870^{\circ} \mathrm{C}-920^{\circ} \mathrm{C}$ for half an hour until a bubble free liquid was formed . The melt was then quenched to room temperature by pouring it on a plane brass plate and pressing it with another brass plate. Finally the vitreous samples were annealed for $3 \mathrm{hrs}$ at $423 \mathrm{~K}$ to relieve residual internal stress and slowly cooled to room temperature. The glasses so obtained were brown in colour with good optical quality and transparency. Details of experimental procedure and calculations are similar to the earlier work [14].

\section{Results and Discussion:-}

X-ray diffraction:-

X-ray diffraction technique has been widely used to characterize inorganic glasses as it readily detects crystals in glassy matrix.

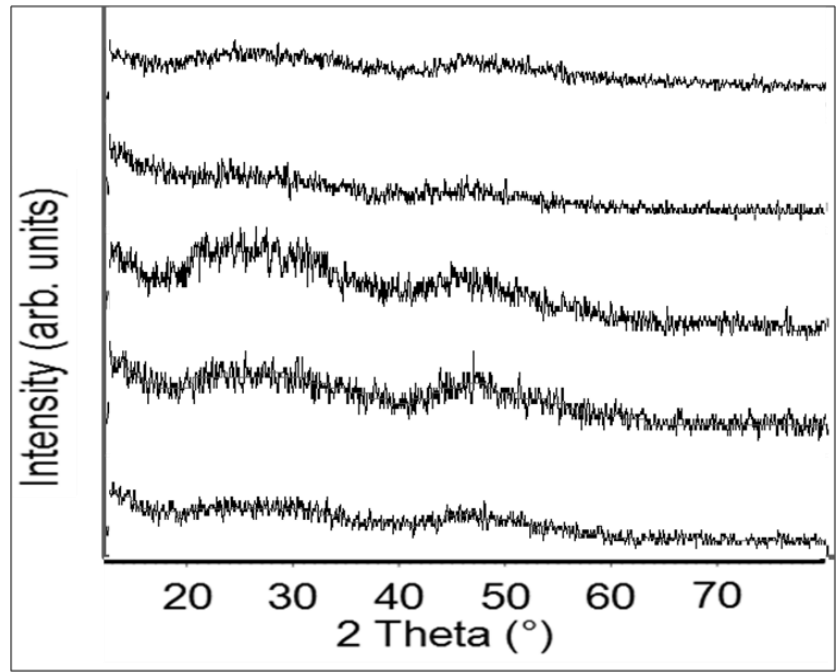

Figure 1:- The XRD patterns of molybdenium doped LNB glass system

Figure 1 represents the XRD patterns for $\mathrm{Li}_{2} \mathrm{O}-\mathrm{Na}_{2} \mathrm{O}-\mathrm{B}_{2} \mathrm{O}_{3}: \mathrm{MoO}_{3}$ compositions of glasses and as can be seen diffraction patterns of all the prepared glasses do not demonstrate any detectable crystalline peaks indicating amorphous or non-crystalline nature of the samples.

\section{Infrared Spectra:-}

The prominent IR bands shown in Fig. 2 are observed for $\mathrm{Li}_{2} \mathrm{O}-\mathrm{Na}_{2} \mathrm{O}-\mathrm{B}_{2} \mathrm{O}_{3}: \mathrm{MoO}_{3}$ glasses and these bands are effectively influenced by the molybdenum content in the glasses network. The molybdenum free glasses exhibited in the regions $1300-1450 \mathrm{~cm}^{-1}, 1100-1200 \mathrm{~cm}^{-1}$. These bands are identified as stretching relaxations of B-O bonds of the trigonal $\mathrm{BO}_{3}$ units. Broad absorption bands are observed at $1050-850 \mathrm{~cm}^{-1}$ and $800-700 \mathrm{~cm}^{-1}$; these bands are 
identified due to stretching vibrations of the $\left[\mathrm{BO}_{4}\right]$ units. When molybdenum is added, two new bands attributed, to $v_{1}$ and $v_{3}$ vibrational modes of $[\mathrm{MoO} 4]^{2-}$ tetrahedral units and $[\mathrm{MoO} 6]^{6-}$ was located at about 810 and $550 \mathrm{~cm}^{-1}$. The bands at 448 and $548 \mathrm{~cm}^{-1}$ were specific to the vibrations of $\mathrm{Li}-\mathrm{O}$ bonds in $\mathrm{Li}_{2} \mathrm{O}$ octahedral units. The summary of various band position of $\mathrm{Li}_{2} \mathrm{O}-\mathrm{Na}_{2} \mathrm{O}-\mathrm{B}_{2} \mathrm{O}_{3}: \mathrm{MoO}_{3}$ is presented in the Table II

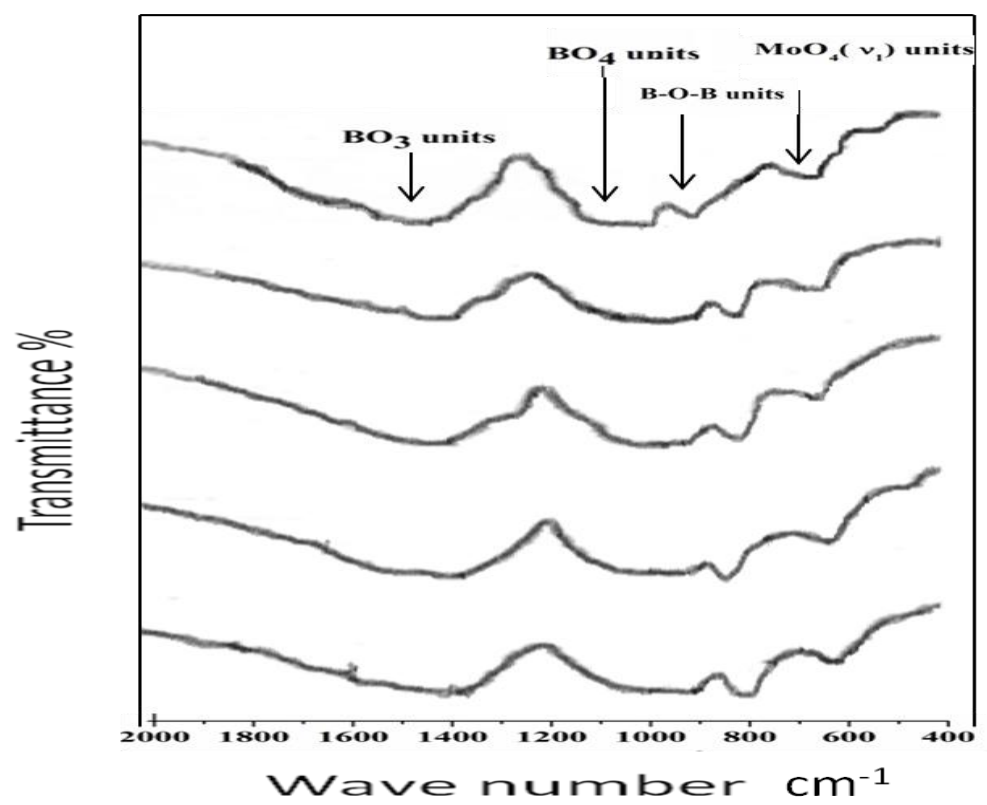

Figure 2:- FTIR spectrum of Lithium-Sodium-Borate glass system containing molybdenium ions of all concentrations.

Table I:- The summary of various band positions of IR spectra of Li2O- -B2O3: MoO3 glasses

\begin{tabular}{|c|c|c|c|c|}
\hline Glass Code & $\begin{array}{c}\text { Trigonal [BO3] units } \\
\left(\mathrm{cm}^{-1}\right)\end{array}$ & $\begin{array}{c}\text { Stretching vibrations } \\
\text { of [BO4] Units } \\
\left(\mathrm{cm}^{-1}\right)\end{array}$ & $\begin{array}{c}\text { v1 vibrational modes } \\
\text { of [MoO4 }]^{-} \\
\text {tetrahedral } \\
\text { units }\left(\mathrm{cm}^{-1}\right)\end{array}$ & $\begin{array}{c}\text { v3 vibrational } \\
\text { modes of } \\
{[\text { MoO4] }} \\
\text { tetrahedral units } \\
\left(\mathrm{cm}^{-1}\right)\end{array}$ \\
\hline M0.2 & 1379 & 1021 & 811 & 694 \\
\hline M0.4 & 1379 & 1019 & 840 & 699 \\
\hline M0.6 & 1376 & 1012 & 820 & 697 \\
\hline M0.8 & 1372 & 1022 & 820 & 698 \\
\hline M1.0 & 1369 & 994 & 914 & 698 \\
\hline
\end{tabular}

\section{Absorption Spectra:-}

The Optical absorption spectra of the $\mathrm{Li}_{2} \mathrm{O}-\mathrm{Na}_{2} \mathrm{O}-\mathrm{B}_{2} \mathrm{O}_{3}: \mathrm{MoO}_{3}$ glasses are recorded at room temperature in the wavelength range $400 \mathrm{~nm}-1400 \mathrm{~nm}$ The Optical absorption spectrum of molybdenum doped lithium sodium borate glass (with $\mathrm{x}=0.6 \mathrm{~mol} \%$ ) is shown in the Fig. 3. The absorption edge is observed to shift towards higher wavelength side. 


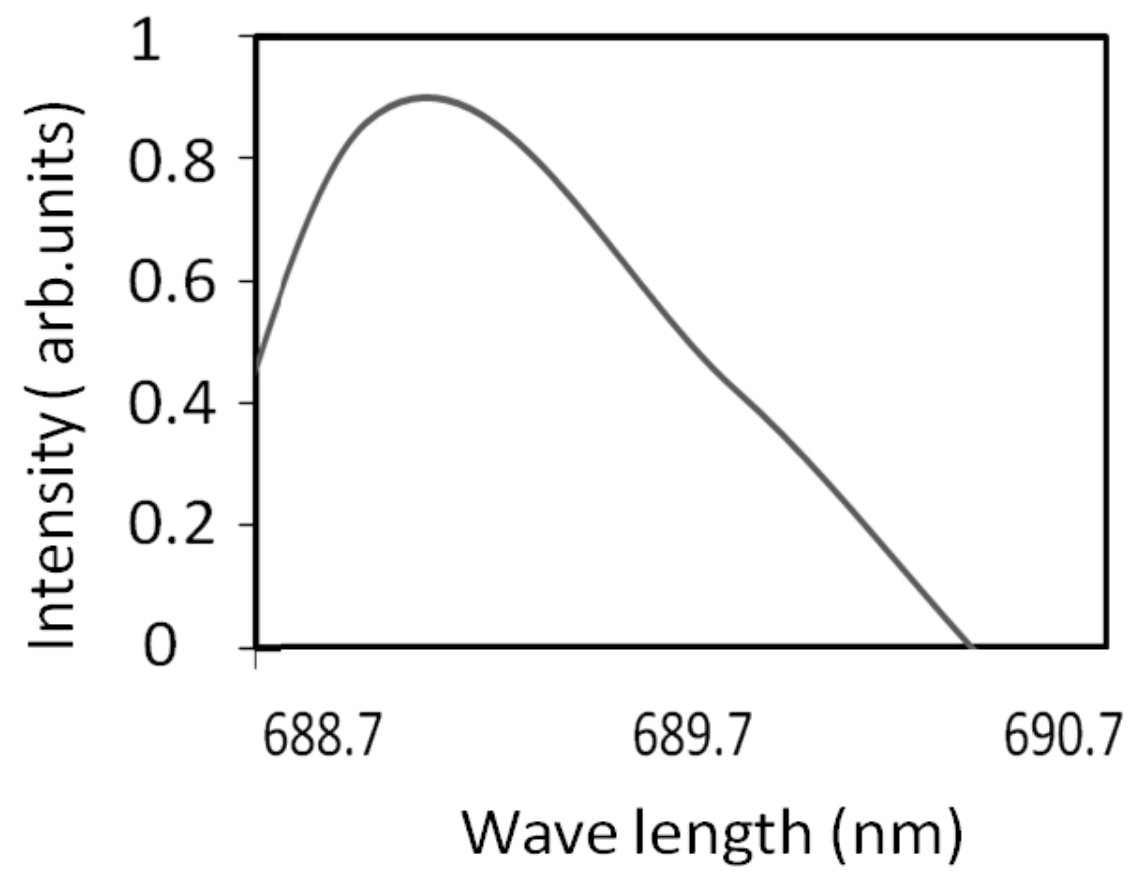

Figure 3:- Optical absorption spectrum of Lithium-Sodium-Borate glass system containing $0.6 \mathrm{~mol} \%$ of $\mathrm{Mo}^{+5}$ ions at room temperature

The spectrum of $\mathrm{MoO}_{3}$ free glasses does not exhibit any absorption band. But small amount of molybdenum is added to glasses matrix shows a broad optical absorption band at about $695 \mathrm{~nm}$ (for $\mathrm{x}=0.6 \%$ ). The intensity of this band was observed to increase gradually as the concentration of $\mathrm{MoO}_{3}$ increased. From the observed absorption edges (fig3a,fig3b,fig3c) direct, indirect band and Urbach energy gap are evaluated and are presented in Table II. The values of direct and indirect band gap energies, decreases from M0.2 to M1.0.

Table II:- Summary of the data on optical absorption spectra $\mathrm{Li} 2 \mathrm{O}-\mathrm{Na}_{2} \mathrm{O}-\mathrm{B}_{2} \mathrm{O}_{3}: \mathrm{MoO}_{3}$ glasses

\begin{tabular}{|c|c|c|c|c|c|}
\hline $\begin{array}{c}\text { Glass } \\
\text { Code }\end{array}$ & $\begin{array}{c}\text { Cut-off } \\
\text { wavelength(nm) }\end{array}$ & Band position(nm) & $\begin{array}{c}\text { Direct band gap } \\
(\mathrm{eV})\end{array}$ & $\begin{array}{c}\text { Indirect band gap } \\
(\mathrm{eV})\end{array}$ & $\begin{array}{c}\text { Urbach Energy } \\
(\mathrm{eV})\end{array}$ \\
\hline M0.2 & 283 & 690 & 3.42 & 3.2 & 1.8071 \\
\hline M0.4 & 288 & 675 & 3.34 & 3.2 & 1.8064 \\
\hline M0.6 & 290 & 695 & 3.28 & 3.0 & 1.8062 \\
\hline M0.8 & 328 & 683 & 3.10 & 2.8 & 1.8060 \\
\hline M1.0 & 388 & 699 & 3.16 & 2.6 & 1.8050 \\
\hline
\end{tabular}

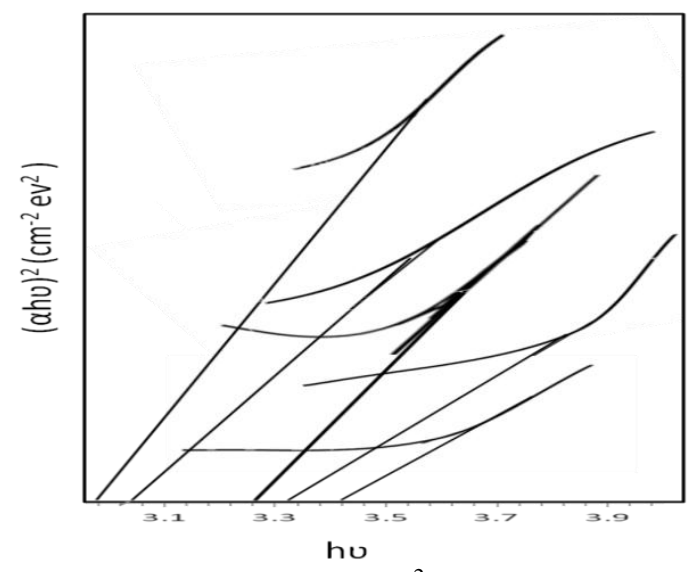

Figure 3(a):- A plot between $(\alpha h v)^{2}$ and $h v$ for glass samples 


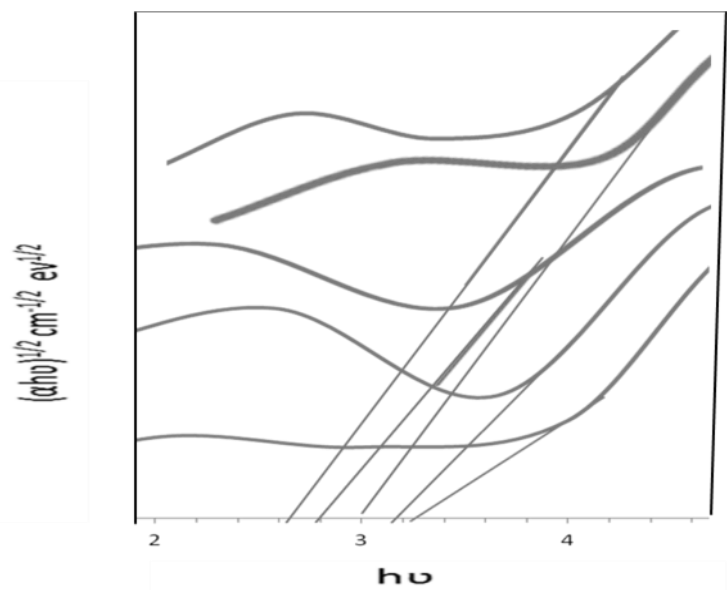

Figure 3(b):- A plot between $(\alpha h v)^{1 / 2}$ and hv for LNBM glass samples

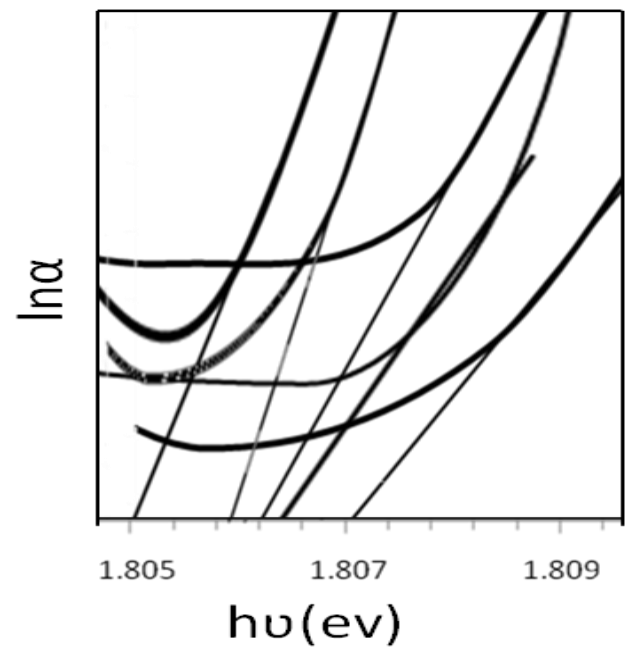

Figure 3 (c):- A plot between $\ln (\alpha)$ and hv for LNBM glass samples

EPR Spectra:-

EPR spectra of $\mathrm{Li}_{2} \mathrm{O}-\mathrm{Na}_{2} \mathrm{O}-\mathrm{B}_{2} \mathrm{O}_{3}: \mathrm{MoO}_{3}$ glasses doped with different concentrations of $\mathrm{MoO}_{3}$ were recorded at room temperature .The EPR spectra of these glasses consist of a main central line surrounded by less intense satellites. The EPR spectra of the glasses recorded at room temperature exhibit signals consisting of a central line surrounded by smaller peaks at about $\mathrm{g}_{\|}=1.811$ and $\mathrm{g}_{\perp}=1.956$ for M0.6 glass system and is shown in Fig. 4 . 


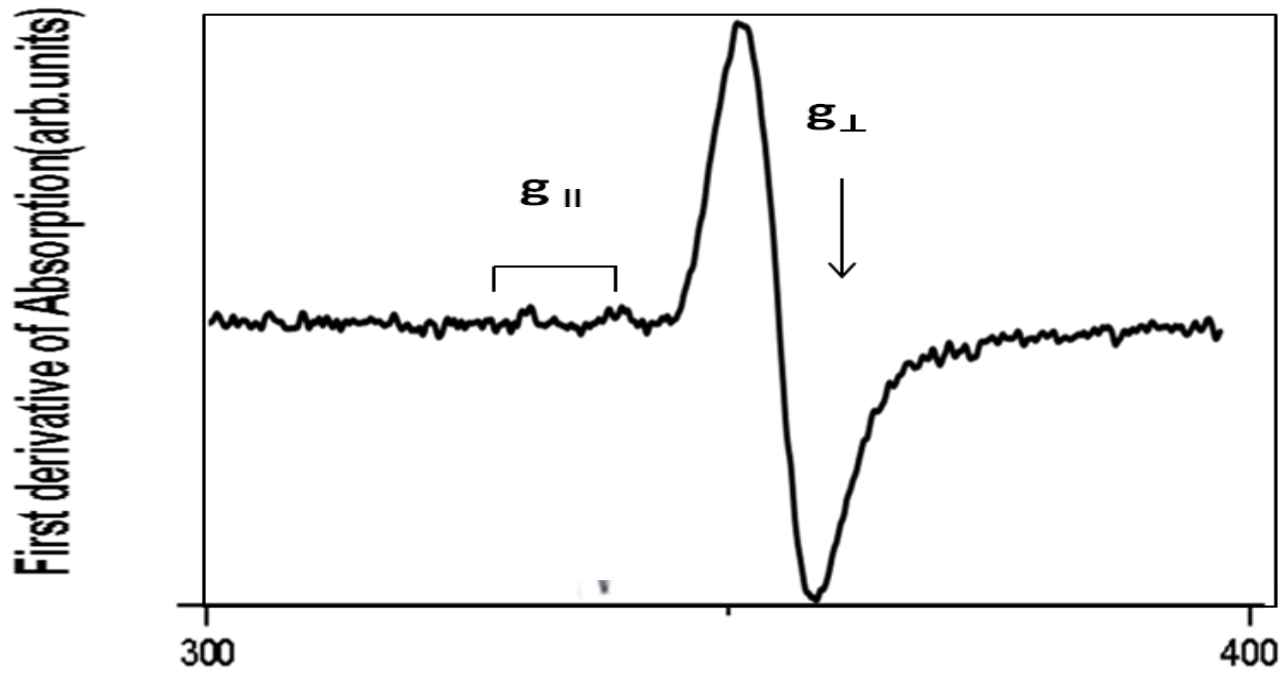

Maneticfield (mT)

Figure 4:- EPR spectra of M0.6 glass sample $(v=9.205 \mathrm{GHz})$

The EPR spectra obtained for the molybdenum ions in the titled glasses are similar to those obtained for various other glass systems [20-22]. The spectra shown in Fig. 4 can best be analyzed using a spin-Hamiltonian of the form: $H=\beta S g B+S A I$, where the symbols have their usual meaning. It contains the electronic Zeeman term ( $\beta$ is the bohr magneton, $S=1 / 2$ the electron spin, $g$ is the $\mathrm{g}$ tensor and $B$ is the applied field), perturbed by the hyperfine coupling term between the unpaired electron and the nuclear spin $I$ of molybdenum ion, A being the hyperfine structure tensor. The central line arises from even molybdenum isotopes $(\mathrm{I}=0)$, while the smaller lines correspond to the hyperfine structure from odd ${ }^{95} \mathrm{Mo}$ and ${ }^{97} \mathrm{Mo}$ isotopes $(I=5 / 2)$. The nuclear magnetic moments of ${ }^{95} \mathrm{Mo}$ and ${ }^{97} \mathrm{Mo}$ being close, so the isotope splitting is not resolved in the EPR spectra. It can be assumed that $\mathrm{Mo}^{5+}$ ions in the glasses studied has an octahedral coordination with a weak axial distortion. An octahedral site with a tetragonal compression usually shows of and $g_{\|}<\mathrm{g}_{\perp}<\mathrm{g}_{\mathrm{e}}(=2.0023)(=2.0023)$ [23].It is found that the values obtained for the glasses under study, are more close to those of the molybdenyl ions. The values of $\mathrm{g} \|$ and $g_{\perp}$ from these spectra have been evaluated and presented in Table III. Further, the g values obtained for these glasses are found to be consistent with the reported values for many other glass systems containing molybdenum ions. $\mathrm{A} \|$ and $\mathrm{A}_{\perp}$ are the parallel and perpendicular components of the hyperfine tensor A. It is observed that the intensity of the resonance signal increases with increase in the concentration of $\mathrm{MoO} 3$.

Table III:- EPR data of Li2O-ZnO-B2O3: MoO3 glasses

\begin{tabular}{|c|c|c|c|c|}
\hline Glass Code & $\mathrm{g}_{\|}$ & $g_{\perp}$ & $\mathrm{A} \|\left(X 10^{-4} \mathrm{~cm}^{-1}\right)$ & $\mathrm{A} \perp\left(\mathrm{X} 10^{-4} \mathrm{~cm}^{-1}\right)$ \\
\hline M0.2 & 1.812 & 1.950 & 107.9 & 1.68 \\
\hline M0.4 & 1.806 & 1.956 & 113.0 & 1.87 \\
\hline M0.6 & 1.811 & 1.956 & 107.3 & 1.88 \\
\hline M0.8 & 1.811 & 1.950 & 109.8 & 1.31 \\
\hline M1.0 & 1.810 & 1.940 & 106.2 & 1.67 \\
\hline
\end{tabular}

The EPR transition can be explained as because of decrease of the effective charge of the surrounding oxygen ligands, there is decrease in their electron donating ability ( $\sigma$-bonds), hence the charge of the central molybdenum remains high. Therefore, this induces the promotion of strong $\pi$-bond with the two axial oxygens of the compressed octahedron hence axially distorted environment is developed. By this the $\mathrm{Mo}(\mathrm{V})$ is strongly displaced in its octahedron so that it adopts a pyramidal configuration $\mathrm{MoO}^{5}$ with a very short Mo-O distance, which would correspond to the molybdenyl ion [24]. 


\section{Conclusions:-}

The conclusions drawn from analysis of the results of the various properties of $\mathrm{Li}_{2} \mathrm{O}-\mathrm{Na}_{2} \mathrm{O}-\mathrm{B}_{2} \mathrm{O}_{3}$ : $\mathrm{MoO}_{3}$ glasses reported in this study are as follows:

-XRD spectra revealed amorphous of the sample.

- The FTIR Spectral studies indicate that the molybdenum ions occupy tetrahedral positions

in higher concentrations.

- The Optical absorption Spectra of $\mathrm{Li}_{2} \mathrm{O}-\mathrm{Na}_{2} \mathrm{O}-\mathrm{B}_{2} \mathrm{O}_{3}: \mathrm{MoO}_{3}$ glasses exhibits bands associated with transitions at

$\mathrm{Mo}^{5+}$ ions, indicating that the molybdenum ions is in pentavalent state, in addition to tetravalent and hexavalent states respectively in these glass samples.

- The EPR Spectra of these glasses exhibit a signal consisting of a triplet separated by smaller satellites. The signal has been identified as arising from tetragonally distorted octahedral positions of $\mathrm{Mo}^{5+}$ ions.

\section{References:-}

1. A. Murali, R.P.S. Chandrasekar, J.L Rao, Physica B. 19, 358 (2005).

2. A. Paul, R.W. Douglas, Phys. Chem. Glasses 6, 212 (1965).

3. J.L. Piguet, \& J.E. Shelly, J.A.M.Ceram. Soc. 68, 450 (1985).

4. A.R. Kumar, J.L Rao, N.O. Gopal, Mater.Res. Bull. 40, 1256 (2005).

5. J.L. Chakradhar, A. Murali, J. Rao, Alloys Compd . 29, 265 (1998).

6. S. M. D. Nery, W. M. Pontuschka, S. Isotani, C. G.Rouse, Phys. Rev. B, 49, 3760 (1994).

7. Bjorn O. Mysen, Journal of Non-Crystalline Solids,95-96(1), 247 (1987).

8. M. Srinivasa Reddy, V. L. N. Sridhar Raja,N. Veeraiah, EPJ Appl. Phys., 37(2), 203(2007).

9. P. Syam Prasad, B. V. Raghavaiah, R. Balaji Rao, C.Laxmi Kanth, N. Veeraiah, Solid State Commun.,132(3-4), 235 (2004).

10. G. D. Khattak, M. A. Salim, A. S. AlHarthi, David J. Thompson, L. E. Wegner, J. Non- Cryst. Solids,212(2-3), 180 (1997).

11. K. S. Sidhu, S. Singh, S. S. Sekhon, S. Chandra, A.Kumar, Phys. Chem. Glasses, 32(6), 255 (1991).

12. A. A Bahgat, M. M. El-Samanoudy, Al. Sabry,Journal of physics and chemistry in solids, 60(12),1921 (1999).

13. Manisha Pal, K Hirota, Y. Tsujigami, H. Sakata,Journal of Physics D: Applied Physics, 34(4), 459(2001).

14. A. M. Milankovic, A. Gajovic, D.E. Day, J. Non-Cryst. Solids. 76, 325(2003).

15. S. Simon, A.C. Nicula, J. Non-Cryst. Solids . 23, 57 (1983).

16. J.F.Lyneh, S.L. Segel, G. Rosenblatt, J. Appl. Phys. 42, 2587 (1971).

17. B. Bridge, N.D. Patel, J.Non-Cryst. Solids 27, 91 (1987).

18. B.V.R.Chowdari, P. P. Kumari, Solid State Ionics 113, 665 (1998).

19. P.Madhusudana Rao,M.Sugathri Lap Lambert Academic Publishing GmbH KG, 2013 Advances in Materials Science and Technologies: AMST-2012 Conference Proceedings,74-81.

20. A. Bals, J. Kliava, J. Phys. Cond. Matter 3 (1991) 6209.

21. M. Haddad, A. Nadiri, A. Biyadi, M.E. Archidi, J.V. Folgado, D.B.Porter, J. Alloys Compd. 188 (1992) 161.

22. D. Boudlich, M. Haddad, A. Nadiri, R. Berger, J. Kliava, J. Non-Cryst. Solids 224 (1998) 135

23. A. Bals, J. Kliava, J. Magn. Reson. 53 (1983) 243.

24. L. Bih , L. Abbas, A. Nadiri, H. Khemakhem, B. Elouadi, J. Mol. Structure 872 (2008) 